\title{
PROMOVENDO UM AMBIENTE FAVORÁVEL À CRIATIVIDADE NAS ORGANIZAÇÕES
}

Eunice M. L. Soriano de Alencar Professora do Programa de Mestrado em Educação da Universidade Católica de Brasília.

RESUMO: Após destacar que a criatividade não deve ser vista apenas como um fenômeno de natureza intrapsíquica, uma vez que muitos são os fatores ambientais que influenciam e mobilizam o potencial criativo, são abordados, neste artigo, distintos aspectos relativos a três eixos centrais. $O$ primeiro diz respeito às características pessoais que se relacionam à criatividade, dando ênfase tanto a atributos pessoais favoráveis como a outros, desfavoráveis. O segundo eixo é composto por alguns fatores do contexto social que afetam a produção criativa, como valores, tradições e sistemas de incentivo e punições. Já o terceiro, chama a atenção para as características de um ambiente de trabalho que se constituem ora como estímulos, ora como obstáculos à criatividade.

ABSTRACT: Creativity is not an intrapsychic phenomenon. It is strongly influenced and mobilized by environmental factors. This article analyses three different groups of factors which affect creativity. The first one is the personal attributes which favour or inhibit creativity. The second is some characteristics of the social context, such as values, traditions, incentive and punishment system, which influence the creative behaviour. A third group of factors refers to the characteristics of the work environment which affect creativity. Both the stimulant factors and the inhibiting factors are described.

PALAVRAS-CHAVE: criatividade, inovação, ambiente de trabalho.

KEY WORDS: creativity, innovation, work environment. 
Há um reconhecimento crescente de que a criatividade é um fator chave para a inovação e sucesso a longo prazo das organizações. Devido à globalização, competição no ambiente de negócios e ritmo acelerado da mudança, as organizações têm sido pressionadas a fazer um melhor uso de seus recursos disponíveis, e aqui incluiríamos a criatividade de seus recursos humanos.

Entretanto, a criatividade, como muitos a idealizam atualmente, é uma ilusão, como lembrou Schwartz, no livro $O \mathrm{mo}$ mento criativo.' Ainda hoje há o predomínio da tendência de se conceber a criatividade apenas como um fenômeno de natureza intrapsíquica, centrada, pois, no indivíduo e dependente de fatores como estilos de pensamento, características de personalidade, valores e motivação pessoais. Essa visão antropocêntrica da criatividade tem sido questionada e o papel vital de fatores do contexto e das forças sociais têm sido posto em relevo. Neste sentido, Csikszentmihalyi lembra que "nós devemos abandonar a visão ptolomeica da criatividade na qual a pessoa está no centro de tudo, para um modelo similar ao de Copérnico, no qual a pessoa é parte de um sistema de mútuas influências e informaçôes ". ${ }^{2}$

Dentre os fatores ambientais que influenciam e inspiram o indivíduo, destacaremos aqui as características de seu ambiente de trabalho, chamando a atenção para distintas condições deste ambiente que podem contribuir para promover a criatividade ou inibir a sua expressão. Não obstante, não podemos também deixar de lembrar que, embora a criatividade seja influenciada poderosamente por características da organização, o indivíduo exerce também uma influência no seu ambiente de trabalho, afetando, entre outros aspectos, o clima psicológico prevalente nesse ambiente. Décadas de pesquisa sobre criatividade têm apontado não só para fatores do ambiente das organizações que influenciam a criatividade tanto positiva quanto negativamente, mas também para elementos pessoais favoráveis e outros desfavoráveis à sua expressão. Indubitavelmente, o comportamento do indivíduo no ambiente de trabalho, ou fora dele, sofre ainda influên- cia profunda de fatores de ordem sóciocultural, como valores e normas da sociedade. Estes contribuem de forma considerável para a emergência, reconhecimento e cultivo da criatividade, ou, pelo contrário, para sua repressão.

\section{Décadas de pesquisa sobre criatividade têm apontado não só para fatores do ambiente das organizações que influenciam a criatividade tanto positiva quanto negativamente mas também para elementos pessoais favoráveis e outros desfavoráveis à sua expressão.}

\section{CARACTERÍSTICAS PESSOAIS QUE SE RELACIONAM COM CRIATIVIDADE}

Várias são as características do indivíduo que se relacionam com a criatividade. $O$ estudo deste aspecto tem mobilizado o interesse da Psicologia desde a década dos 50 , quando Guilford, ${ }^{3}$ que vinha realizando pesquisas sobre a inteligência, identificou um componente da estrutura do intelecto: o pensamento divergente, que se distingue sobretudo pela riqueza e originalidade das idéias. Foi também Guilford quem apontou para o descaso da Psicologia norte-americana pelo estudo da criatividade, que, em seu entender, merecia
1. SCHWARTZ, J. O momento criativo. Mito e alienação na ciência moderna. São Paulo: Editora Best Seller, 1992.

2. CSIKSZENTMIHALYI, N. M. Society, culture, and person: A systems view of creativity. Em R. Sternberg (Ed.). The nature of creativity. Cambridge, MA: Cambridge University Press, 1988, p. 336 .

3. GUILFORD, J. P. Creativity. American Psychologist. v. 4, p. 444-454, 1950. 
maior atenção dado o seu papel crítico para o progresso. Desde então, tem sido especialmente os atributos pessoais relevantes para a expressão da criatividade que vêm mobilizando o interesse da Psicologia, que se expandiu apenas em anos recentes para englobar também fatores externos ao indivíduo, como o seu ambiente social.

\section{A eriatividade floresce mais quande • indivíduo realiza tarefas mobilizade mais pelo prazer e satisfação do que pela obrigação e dever.}

Quanto às características pessoais, salientaremos inicialmente as que se relacionam de forma negativa com a expressão da criatividade e que foram apontadas sobretudo por Amabile e colaboradores, em estudos realizados no Centro para Liderança Criativa, dos Estados Unidos, ${ }^{4}$ através de pesquisas com amostras de profissionais de distintas organizações. Estas são:

4. AMABILE, T. M. \& SENSABAUGH, S J. Public and private creativity. In: B. G. Whiting \& G. T. Solomon (Eds.), Key issues in creativity, innovation \& entrepreneurship. Buffalo, N. Y.: Bearly 1989; HILL, K. G. \& AMABILE, T. M. A social psychology perspective in creativity: Intrinsic motivation and creativity in the classroom an workplace. In: S. G. Isaksen, M. C Murdock, R. O. Firestien \& D. J. Treffinger (Eds.), Understanding and recognizing creativity. The emeroence of discipline. Norwood, N. J.: Ablex, 1993.

5. FROST, P. J. The many facts of creativity. In: C. M. Ford \& D. A. Gioin (Eds.), Creative action in organizations. Londres: Sage Publications, 1995
- Falta de motivação: indivíduo descomprometido e sem interesse pelo trabalho sob sua responsabilidade.

- Falta de habilidades ou experiência: mento; experiência ou habilidades limitadas para desempenhar de forma adequada a sua função.

- Inflexibilidade: pessoa que se caracteriza por opiniões ou preconceitos arraigados, com pouca predisposição à mudança. pessoa com pouco ou nenhum conheci-
- Socialmente despreparada: a criatividade é também inibida em pessoas que têm dificuldade de interagir, de trocar idéias e informações, e de expor as suas idéias seja para colegas, seja para outras audiências, que poderão contribuir com distintas perspectivas sobre as idéias apresentadas.

Por outro lado, características opostas às anteriores têm sido observadas em profissionais que se destacam pela produção criativa, como por exemplo:

- Um elenco de traços de personalidade: pessoas que se caracterizam pela iniciativa, independência de pensamento e ação, flexibilidade, persistência e autoconfiança têm maiores chances de aproveitar as oportunidades para expressar e desenvolver idéias criativas. De especial relevância para a expressão da criatividade é a disposição para correr riscos e aprender com os próprios erros. A coragem é, pois, indubitavelmente um atributo de fundamental importância, uma vez que a criatividade implica lidar com o desconhecido. Neste sentido, Frost considera que "atos criativos são atos de coragem. Primeiro porque o criador de uma inovação técnica ou social está entrando em águas desconhecidas e provavelmente receberá comentários conflitantes sobre o valor da nova idéia. Segundo, porque o criador encontrará oposição ou hostilidade quando a idéia for apresentada e introduzida no sistema; terceiro, porque ao longo do caminho, para uma possível aceitação da idéia, o criador terá que investir uma grande energia pessoal no processo de ter a inovação aceita; quarto, porque atos criativos podem falhar e algumas vezes ameaçam a carreira de seus responsáveis".

- Auto-motivação: pessoa internamente motivada para a tarefa, que se envolve e se dedica à mesma, impulsionada por um interesse apaixonado pelo que faz. A criatividade floresce mais facilmente quando o indivíduo realiza tarefas mobilizado mais pelo prazer e satisfação do que pela obrigação e dever. 
- Habilidades cognitivas especiais: estas incluem tanto a fluência, a flexibilidade e a originalidade de idéias, que caracterizam o pensamento divergente, como o raciocínio analítico e crítico.

- Expertise na área: embora uma preparação sólida não seja uma garantia para a criatividade, é indubitável que quanto maior a bagagem de conhecimento e experiência, maiores as chances de se produzirem idéias que sejam inovadoras e de valor.

- Habilidades grupais: estas também são necessárias, uma vez que tanto o isolamento como o contato social têm o seu papel durante o processo de criação. Como lembram Montuori e Purser, ${ }^{6}$ muitos indivíduos que se destacam por sua produção criativa parecem alterar períodos de isolamento com períodos de discussão e contatos sociais. Estes autores fazem referência a pesquisas realizadas nos Laboratórios Bell, dos Estados Unidos, mostrando que, nos diferentes estágios do processo de invenção por parte de cientistas mais inovadores, há momentos em que se prefere trabalhar isoladamente e outros em que se opta por ter contato com colegas, com quem se possa falar sobre os projetos de trabalho e ouvir o que os seus pares pensam sobre o problema com que se está trabalhando.

\section{FATORES DE ORDEM SÓCIO- CULTURAL}

A criatividade ocorre no contexto social e depende de processos de pensamento que têm suas raízes mais profundas na cultura. Tanto as normas, como as tradições, os valores, os tabus, os sistemas de incentivo e punições afetam sua expressão. O papel crucial do ambiente social é inquestionável e tem sido apontado pelos mais diversos autores, como Stein que assim se expressou: "Estimular a criatividade envolve não apenas estimular o indivíduo, mas também afetar o seu ambiente social e as pessoas que nele vivem. Se aqueles que circundam o indivíduo, não valorizam a criatividade, não oferecem o ambiente de apoio necessário, não aceitam o trabalho criativo quando este é apresentado, então é possível que os esforços criativos do indivíduo encontrem obstáculos sérios, senão intransponiveis"."

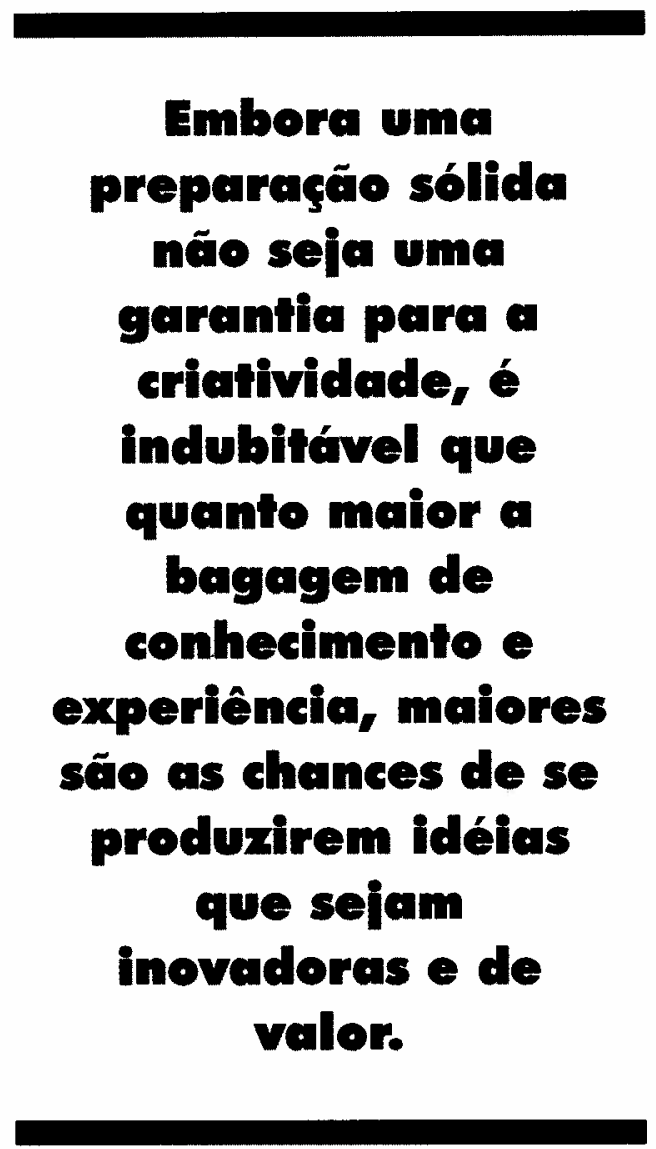

Nota-se que até mesmo o que é considerado criativo sofre influência do contexto histórico-social. Neste sentido, não se pode falar de uma criatividade universal. O que é considerado criativo varia de um momento da História para outro, de um contexto sócio-cultural para outro. Tanto a história da ciência como das artes estão recheadas de exemplos que chamam a atenção para grandes obras ou mesmo descobertas que foram rejeitadas no momento em que surgiram para serem aceitas e aplaudidas décadas após a sua produção. A música de J. S. Bach, por exemplo, foi ignorada por mais de 50 anos após a sua morte, quando, então, mudanças ocorreram na sociedade, levando a uma maior sensibilidade à produção musical deste compositor. Outros
6. MONTUORI, A. \& PURSER, R. E. Deconstructing the lone genius myth Toward a contextual view of creativity. Joumal of Humanistic Psychology. v. 35 , n. 3, p.69-112, 1995.

7. STEIN, M. J. Stimulating creativity. Individual procedures. New York Academic Press, 1974. 
exemplos da área de artes plásticas foram Rembrandt e Botticelli, cujo talento excepcional só foi reconhecido anos após a morte destes dois grandes gênios. $\mathrm{Na}$ área das descobertas científicas, poder-se-ia lembrar a reação de descrença a que Pasteur foi alvo quando apresentou a sua teoria da reprodução dos microrganismos na Academia de Ciências de Paris. Röntgen foi ridicularizado quando anunciou a sua descoberta do Raio $\mathrm{X}$ e Harvey lutou vinte anos para que a sua teoria da circulação sanguiínea fosse aceita. ${ }^{8}$

A culfura
organizacional inclui
os valores
predominantes no
ambiente de
trabalho, valores
estes que se espelham
sobretude nas ações
de seus dirigentes e
alfos executivos.

8. BEVERIDGE, W. I. B. The art of scientific investigation. New York: Vintage Books, 1988;WEISBERG, R. W. Creativity; Beyond the myth of genius. New York: Freeman, 1993.

9. COLE, R. E. Work and leisure in Japan. California Management Review, v. 34, n. $3, p .51-63,1992$

10. OUCHI, W. Japanese management: The art of self-regulation. Em G. Morgan (Ed.), Creative organization theory. Newbury Park, California: Sage, 1989. buem para justificar as longas horas de trabalho comuns em empresas japonesas (os japoneses trabalham em média 200 horas anuais a mais do que os americanos e ingleses e 400 horas a mais que os alemães e franceses) e o reduzido número de dias de férias que usufruem (embora tenham direito a 15,5 dias ao ano, usualmente utilizam apenas uma média de 8,2 dias de férias). Como o traba- lho é tradicionalmente atribuído a grupos e não a indivíduos, tende-se a considerar que a ausência irá prejudicar ou tornar mais lentas as atividades do grupo. Ademais, $o$ desejo de usar todos os dias de férias é visto como um ato de deslealdade. ${ }^{9}$

Um outro exemplo que também ilustra como as normas da cultura podem afetar o comportamento no trabalho é apresentado por Ouchi no artigo $A$ administração japonesa: a arte de auto-regulação. ${ }^{10}$ Nesse artigo, $o$ autor discute a ideologia das organizações japonesas que tende a facilitar um intenso comprometimento no trabalho, levando cada funcionário a se identificar com a empresa e sua missão, através de uma série de estratégias que fazem com que o indivíduo tenha a organização como sua própria família. Uma dessas estratégias descrita por Ouchi diz respeito a uma cerimônia de iniciação de novos funcionários por um banco japonês. Lembra ele que há uma cerimônia formal no auditório da instituição, onde todos os novos funcionários sentam na primeira fila, tendo próximo os seus pais e demais familiares. Nessa cerimônia, cada um é exortado a atender às expectativas da empresa. Faz parte ainda do evento, um dos representantes dos pais proferir um discurso para agradecer ao banco pela oportunidade dada ao filho e reafirma junto a este a importância de se manter leal à sua nova família (que é a instituição), tanto quanto à sua família biológica. Para finalizar, um representante dos novos funcionários também agradece aos pais e à instituição pelo apoio e reafirma o compromisso de se empenhar no sentido de dar o melhor de si para alcançar as expectativas da instituição.

Os dois exemplos citados chamam a atenção para a relevância de práticas culturais que têm influência no comportamento do indivíduo no seu local de trabalho, além de imprimirem uma orientação no estilo de gerenciamento da empresa.

\section{O AMBIENTE DE TRABALHO E A CRIATIVIDADE}

Em face do impressionante processo de globalização e competição acirrada que caracteriza o mundo das organizações, estas vêm sofrendo uma enorme pressão para se 
manterem em um processo permanente de inovação. Como a origem da inovação reside nas idéias criativas dos indivíduos, a criatividade tem recebido uma atenção crescente. Ela tem sido apontada como uma habilidade humana crítica, que deve ser canalizada e fortalecida a favor do sucesso da organização.

Vários autores ${ }^{11}$ têm apontado as características de uma organização que se relacionam com a criatividade. Dado o papel decisivo da criatividade para o êxito das organizações no seu processo de lidar com a mudança, incerteza, instabilidade, concorrência, e promover de forma sistemática a inovação, é necessário que os dirigentes estejam atentos às condições prevalentes no seu ambiente de trabalho, no sentido de desfazer possíveis barreiras à criatividade, maximizando as oportunidades para a sua expressão.

Porém, o que tem sido observado é que muitas organizações tendem a ignorar o potencial para a competência, responsabilidade e produtividade, estimulando mais a dependência e a passividade do que a iniciativa e a criatividade. As necessidades básicas de reconhecimento, apoio e segurança, que deveriam ser atendidas no ambiente de trabalho, são, muitas vezes, ignoradas, afetando a motivação para o trabalho e contribuindo para manter adormecido o potencial para a criatividade.

Não é raro a presença da intransigência e do autoritarismo, com ausência de espírito de equipe, de apoio para se colocar novas idéias em prática, vendo-se com suspeita ou desconfiança qualquer idéia inovadora. Por outro lado, as características do clima predominante no ambiente de trabalho são captadas facilmente através de sensores que todo ser humano dispõe e que estão permanentemente em ação, captando e filtrando informações a respeito do ambiente psicológico ao seu redor, das reações do grupo às suas idéias e a si mesmo e da extensão em que pode ou não confiar em seus colegas de trabalho. Nota-se que se a pessoa considera que pode ser criticada, ridicularizada, punida ou ameaçada pelas suas idéias, ou se ela se sente pouco valorizada no ambiente de trabalho, dificilmente vai se interessar em expressar idéias novas e fazer uso de suas potencialidades criativas em prol da organização.
Dentre os requisitos que caracterizam uma organização criativa, salientaremos aqui especialmente a presença de líderes criativos e o cultivo de um ambiente criativo. Caberia aos líderes imprimir as condições

que facilitariam a emergência das idéias criativas, promovendo um ambiente de abertura e apoio às idéias inovadoras. Tanto Hitt, há mais tempo, ${ }^{12}$ como Locke e Kirkpatrick, mais recentemente, ${ }^{13}$ consideram estes fatores como chaves para a criatividade nas organizações, dando destaque à cultura organizacional e a forma como seus dirigentes a imprimem. A cultura organizacional inclui os valores predominantes no ambiente de trabalho, valores estes que se espelham sobretudo nas ações de seus dirigentes e altos executivos. Os valores, por sua vez, implicariam normas ou maneiras esperadas de ação. Para facilitar a expressão da criatividade nas organizações, Locke e Kirkpatrick sugerem os seguintes meios:

1. O líder deve formular uma visão que enfatiza a importância da criatividade, comunicando esta visão continuamente a todos os empregados.

11. ALENCAR, E. M. L. S. Criatividade (segunda edição). Brasília: Editora da Universidade de Brasilia, 1995 A gerência da criatividade. São Paulo: Makron Books, 1996; AMABILE, T. M. Discovering the unknowable, managing ther unmanageable. In: C. M. Ford \& D. A. Gioia (Eds.), Creative action in organizations. Londres: Sage Publications, 1995; BRUNO-FARIA, M. F. \& ALENCAR, E. M. L. S. Estímulos e obstáculos à criatividade no ambiente de trabalho. Revista de Administração, v. 31, no. 2, p. 50 - 61, 1996; HITT, M. A. The creative organization; Tomorrow's survivor. Journal of Creative Behavior, v.9, n. 4, p. 263-290, 1975; LOCKE, E. A. \& KIRKPATRICK, S. A. Promoting creativity in organizations. Em C. M. Ford \& D. A. Gioia (Eds.), Creative action in organizations. Londres: Sage Publications, 1995.

12. HITT, M. A. Op. cit.

13. LOCKE, E. A. \& KIRKPATRICK, S. A. Op. cit. 
2. Uma cultura criativa deve ser implementada através de passos específicos que favoreçam a implementação da $v i$ são. Estes incluem: (a) seleção de pessoas que se caracterizam, entre outros aspectos, por sólida preparação e uso dos processos de pensamento criativo; (b) possibilidades amplas de treinamen-

De especial
relevância para a
expressão da
criatividade é a
disposiģão para
correr riscos e
aprender com os
próprios erros. A
coragem é, pois,
indubifavelmente um
atributo de
fundamental
importância, uma vez
que a ariatividade
implica lidar com •
desconhecido.

14. NORIUS, H. The Young \& Rubicam traveling creative workshop. Englewood Cliffs, N. J.: Prentice Hall, 1990

15. AMABILE, T. M. Op. cit.

16. HILL, K, G. \& AMABILE, T. M. Op. cit. idéias e produtos criativos, com ausência de punições a fracassos eventuais.

Idéias similares às anteriores são ainda apontadas por Norius ${ }^{14}$ que também desta- ca cinco maneiras de se alcançar um ambiente ideal para a criatividade:

1. o comprometimento com as metas da organização, que deve ser permanentemente alimentado;

2. o cultivo de uma cultura na organização. que se caracteriza pela flexibilidade, comunicação, desafio, prazer e sentimentos de pertencimento;

3. a provisão constante de incentivos e prêmios às novas idéias e produção criativa:

4. manter-se em um processo permanente de renovação; e

5. possibilitar aos funcionários treinamento e recursos para o desenvolvimento de projetos.

As condições no ambiente de trabalho que têm impacto na criatividade foram também pesquisadas por Amabile e colaboradores que identificaram tanto as qualidades do ambiente que promovem a criatividade como as condições que a inibem. Entre as primeiras, situam-se liberdade e controle, estilo de gerenciamento flexibilidade, recursos para se colocar a idéia em prática, apoio do grupo de trabalho, encorajamento, reconhecimento e feedback, tempo adequado para realização das tarefas. Por outro lado, dentre os fatores que bloqueiam a criatividade, estariam um clima organizacional pobre, excesso de avaliação e pressão, recursos insuficientes, ênfase no status quo, pressão de tempo, competição acirrada e projeto inadequado de gerenciamento.

Amabile sintetiza as condições que facilitam a criatividade, lembrando que " $n i$ veis mais altos de criatividade provavelmente ocorrerão em pessoas flexiveis, com um background relevante de conhecimento, que gostam do que fazem e que trabalham em um ambiente onde se sentem desafiados, encorajados a correr os riscos que a implementação de uma nova idéia implica e apoiados em sua autonomia". "s

Um modelo de inovação organizacional, com três componentes básicos foi proposto por esta autora, juntamente com Hill, ${ }^{16}$ a partir de estudos realizados no contexto de grande número de organizações. Estes três componentes são:
- Recursos: dizem respeito a fundos, materiais, pessoas e informações disponíveis para se realizar o trabalho. Tais re- 
cursos, entretanto, podem ou não ser usados de forma criativa.

- Técnicas: incluem competências no gerenciamento da inovação, presentes nos distintos níveis da organização e voltadas para a concepção, desenvolvimento e implementação de idéias criativas.

- Motivação: é considerada o componente mais importante tanto no âmbito do indivíduo quanto da organização. Embora sejam os recursos e competências de gerenciamento que tornam a inovação possível, a motivação é o elemento catalisador das ações voltadas para a inovação.

O nosso interesse por esta área levounos a investigar, junto a funcionários de distintas organizações, as características de uma organização que se constituem como estímulos à criatividade no ambiente de trabalho. ${ }^{17}$ Dentre estes, tanto aspectos ligados à estrutura da organização, como outros relacionados às características da chefia e ainda aos recursos disponíveis foram lembrados pelos funcionários, dos quais se destacaram especialmente:

- Suporte da organização: este incluiria o reconhecimento do trabalho criativo, mecanismos para o desenvolvimento de novas idéias e uma cultura voltada para a inovação.

- Estrutura organizacional: uma estrutura favorável à criatividade se caracterizaria por um número limitado de hierarquias, normas flexíveis, menos burocracia e descentralização do poder decisório.

- Apoio da chefia: uma postura de receptividade, flexibilidade, aceitação e estímulo às novas idéias, paralelamente ao respeito às opiniões divergentes caracterizariam uma chefia que favorece à expressão da criatividade.

- Suporte do grupo de trabalho: relacionamento interpessoal favorável e estimulante a idéias novas, diálogo e confiança entre os membros das equipes, trocas de experiências entre membros e equipes.

Outros fatores como recursos tecnológicos e materiais, possibilidade de treinamento e presença de desafios, embora também importantes, foram menos ressaltados por esta amostra.
Os nossos dados têm identificado também uma insatisfação por parte de um número significativo de profissionais de empresas diversas quanto ao seu ambiente de trabalho. $O$ excesso de burocracia, inexistência de espírito de equipe, falta de integração entre setores, precário sistema

\section{A criatividade ocorre no contexte social e depende de processos de pensamento que têm suas raízes mais profundas na culfura. Tanto as \\ normas, come as tradições, os valores, os tabus, os sistemas de incentivo e punições afetam sua expresscîo.}

de comunicação, são algumas das queixas comuns que levam o indivíduo a não encontrar significado no trabalho e a se sentir desestimulado a fazer uso de sua energia criativa em favor da organização.

Portanto, é necessário que uma plataforma para a criatividade individual esteja presente no ambiente das organizações. Essa plataforma tem como base a presença de sentimentos de confiança e respeito, a harmonia nas equipes, a prática das virtudes de compartilhar idéias, respeitar as diferenças, valorizar o trabalho do indivíduo e do grupo, reconhecer as potencialidades e oferecer oportunidades para a produção e fertilização de idéias.
17. BRUNO-FARIA, M. F. \& ALENCAR, E M. L. S. Op. cit. 